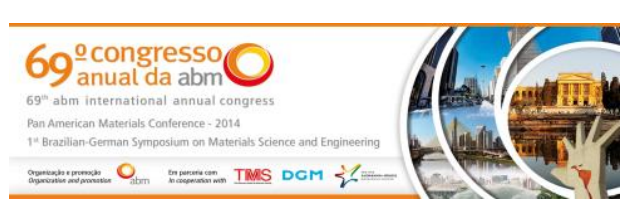

Tema: Metalurgia física e comportamento de materiais em temperaturas elevadas

\title{
INFLUÊNCIA DA ATMOSFERA DUPLA E SIMPLES NA CORROSÃO DE LIGAS DE FERRO A $600^{\circ} \mathrm{C}^{*}$
}

Daniel Massari de Souza Coelho ${ }^{1}$ Axel Kranmann ${ }^{2}$ Fernando Rizzo ${ }^{3}$

\section{Resumo}

Ligas de ferro com diferentes teores de cromo, carbono e cobalto foram expostas a uma condição de atmosfera dupla, onde um lado da amostra é exposto ao vapor d'água e o outro lado a gases ricos em $\mathrm{CO}_{2}$, semelhantes aos encontrados em usinas termelétricas a carvão que utilizam o processo de oxicombustão. Os ensaios realizados em condição de atmosfera dupla a $600^{\circ} \mathrm{C}$ foram comparados com ensaios realizados em atmosfera simples onde todos os lados das amostras foram expostos ao mesmo gás. As amostras foram caracterizadas para comparar a corrosão em atmosferas simples e dupla e para analisar a influência dos elementos de liga na oxidação destes materiais utilizados em processos em altas temperaturas.

Palavras-chave: Corrosão; Aço; Altas-temperaturas; Oxicombustão.

\section{INFLUENCE OF THE DUAL AND SINGLE ATMOSPHERE IN THE CORROSION OF FE ALLOYS AT $600^{\circ} \mathrm{C}$}

\section{Abstract}

Steel alloys with different chromium, carbon and cobalt content were exposed to a dual atmosphere condition were one side of the samples is exposed to water vapor and the other side to $\mathrm{CO}_{2}$ rich gases, similar to gases found in oxyfuel power plants. Tests in dual condition were compared to tests in single condition where all sides of the sample were exposed to the same gas. The samples were characterized to compare the corrosion in single and dual atmospheres and to analyze the alloying elements influence in the oxidation of these materials used in high temperature processes.

Keywords: Corrosion; Steel; High temperature; Oxyfuel.

1 Engenheiro metalúrgico, MSC Doutorando, PUC-Rio, Rio de Janeiro, RJ, Brasil.

2 Fisico, Dr. rer. nat. Max-Planck-Institut für Metallforschung, Diretor da Divisão 5.1, Bundesanstalt für Materialforschung und-prüfung, Berlim, Alemanha

3 Engenheiro metalúrgico, PhD., Professor, PUC-Rio, Rio de Janeiro, RJ, Brasil.

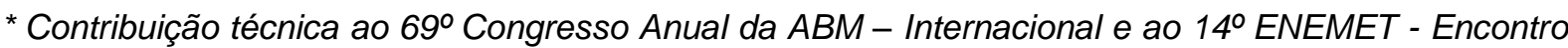
Nacional de Estudantes de Engenharia Metalúrgica, de Materiais e de Minas, 21 a 25 de julho de 2014, São Paulo, SP, Brasil.
} 


\section{INTRODUÇÃO}

A crescente demanda mundial por energia e a necessidade do controle de emissão de gás carbônico $\left(\mathrm{CO}_{2}\right)$, principal gás responsável pelo aquecimento global, exigem o desenvolvimento de novas tecnologias para a produção de energia com menor emissão de $\mathrm{CO}_{2}$. $\mathrm{O}$ uso de fontes alternativas na produção energética está aumentando, mas não é suficiente para suprir a demanda, portanto o uso de combustíveis fósseis ainda é necessário [1-3]. Neste contexto, o uso da tecnologia oxicombustão (Oxyfuel) em usinas a carvão em conjunto com a captura e sequestro de carbono (CCS) surge como uma alternativa às usinas convencionais a carvão, pois não emite $\mathrm{CO}_{2}$ na produção de energia. $\mathrm{O}$ processo de oxicombustão difere basicamente do convencional pela queima de $\mathrm{O}_{2}$ puro e gás reciclado ao invés de ar [4]. Com isso uma atmosfera rica em $\mathrm{CO}_{2}$ e $\mathrm{H}_{2} \mathrm{O}$ é formada no boiler, podendo aumentar a corrosão dos materiais em contato com o gás.

Utilizando uma atmosfera similar às encontradas em usinas que utilizam o processo de oxicombustão contendo $70 \mathrm{vol} \% \mathrm{CO}_{2}$ e $30 \mathrm{vol} \% \mathrm{H}_{2} \mathrm{O}$ em temperaturas entre $500^{\circ} \mathrm{C}$ e $700^{\circ} \mathrm{C}$, Hünert et al. $[5,6]$ investigaram aços com 1,9, 12 e $24 \% \mathrm{Cr}$ a 80 bar durante 1000h. Nos aços com $1 \% \mathrm{Cr}$ a espessura da camada de óxido aumentou com o aumento da temperatura, mas o mesmo não foi verificado para aços com teores de cromo maiores que $9 \%$. No aço VM12, por exemplo, a camada mais espessa foi observada quando a oxidação ocorreu a $600^{\circ} \mathrm{C}$ e a menor espessura ocorreu a $700^{\circ} \mathrm{C}$. O mesmo comportamento de formação de camadas de óxido menos espessas em temperaturas mais elevadas também foi observado por Pirón Abellán et al.[7]. Os autores relacionaram este comportamento à maior mobilidade do $\mathrm{Cr}$ à $600^{\circ} \mathrm{C}$ que favorece a formação de camadas protetoras ricas em cromo.

Usando uma atmosfera com a mesma composição, $70 \% \mathrm{CO}_{2}+30 \% \mathrm{H}_{2} \mathrm{O}$, e comparando com atmosferas contendo ar, $\mathrm{Ar}+30 \% \mathrm{H}_{2} \mathrm{O}$ e $\mathrm{Ar}+30 \% \mathrm{H}_{2} \mathrm{O}=3 \% \mathrm{O}_{2}$, $\mathrm{Mu}$ et al. [8] observaram que a corrosão na atmosfera $\mathrm{com} \mathrm{CO}_{2}$ é mais severa. Resultado similar foi relatado por Meier at al. [9], que relacionaram maior corrosão em atmosferas contendo $\mathrm{CO}_{2}$ à formação de carbonetos que diminuem o fluxo de $\mathrm{Cr}$ para a interface metal/óxido, desfavorecendo a formação de uma camada protetora rica em $\mathrm{Cr}$.

Ensaios em atmosfera dupla foram realizados por Nakagama et al. [10] utilizando aços ferríticos com 2, 9 e $12 \% \mathrm{Cr}$ em amostras de $10 \mathrm{~mm}$ de espessura em atmosferas duplas a $600^{\circ} \mathrm{C}$ contendo ar de um lado e uma mistura de $50 \% \mathrm{H}_{2} \mathrm{O}$ e $50 \% \mathrm{Ar}$ do outro em ensaios de até $2000 \mathrm{~h}$. Os resultados foram comparados ao de amostras oxidadas somente com ar e indicaram uma grande diferença tanto na oxidação interna quanto externa entre as duas condições. As amostras oxidadas em atmosferas duplas apresentaram taxas de corrosão maiores que as amostras oxidadas em atmosferas simples. A escala do lado do ar nos ensaios em atmosferas duplas apresentou uma morfologia semelhante às amostras oxidadas somente com vapor d'água, mas com uma camada externa de hematita $\left(\mathrm{Fe}_{2} \mathrm{O}_{3}\right)$. A permeabilidade do hidrogênio também foi medida pelos autores e observou-se que a permeabilidade diminui com o aumento de $\mathrm{Cr}$ na liga.

Yang et al. [11-14] fizeram diversos estudos em aços inox ferríticos utilizados em interconectores para SOFC em atmosferas duplas e simples. Em todos os estudos foi verificado que as taxas de corrosão e as morfologias das escalas eram diferentes nos ensaios realizados em atmosferas simples e duplas. Nos ensaios em atmosferas duplas, foi observada a formação de nódulos de hematita ou espinélio, dependendo da composição do aço, enquanto que em atmosfera simples houve a formação de

\footnotetext{
* Contribuição técnica ao $69^{\circ}$ Congresso Anual da ABM - Internacional e ao 14ํㅡㄹ ENEMET - Encontro Nacional de Estudantes de Engenharia Metalúrgica, de Materiais e de Minas, 21 a 25 de julho de 2014, São Paulo, SP, Brasil.
} 


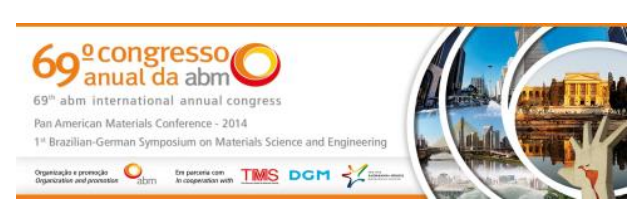

As amostras para os ensaios em atmosferas duplas têm $3 \mathrm{~mm}$ de espessura e $20 \mathrm{~mm}$ de diâmetro. Nos ensaios em atmosfera simples, foram utilizadas amostras retangulares com cerca de $2 \mathrm{~mm}$ de espessura, $10 \mathrm{~mm}$ de largura e $15 \mathrm{~mm}$ de comprimento.

Para analisar a corrosão em atmosfera dupla, foi projetado um equipamento especialmente para estes ensaios. O equipamento consiste de dois tubos de $\mathrm{Al}_{2} \mathrm{O}_{3}$ com flanges nas extremidades onde fica a amostra. A vedação é feita com anéis de ouro e os tubos são conectados com uma luva de aço inox (Figura 1). Os gases foram injetados dentro dos tubos de alumina por dois tubos de aço inox e a exaustão é feita na outra extremidade dos tubos de alumina. Este equipamento foi parcialmente envolvido por um forno cilíndrico para atingir a temperatura desejada de $600^{\circ} \mathrm{C}$.

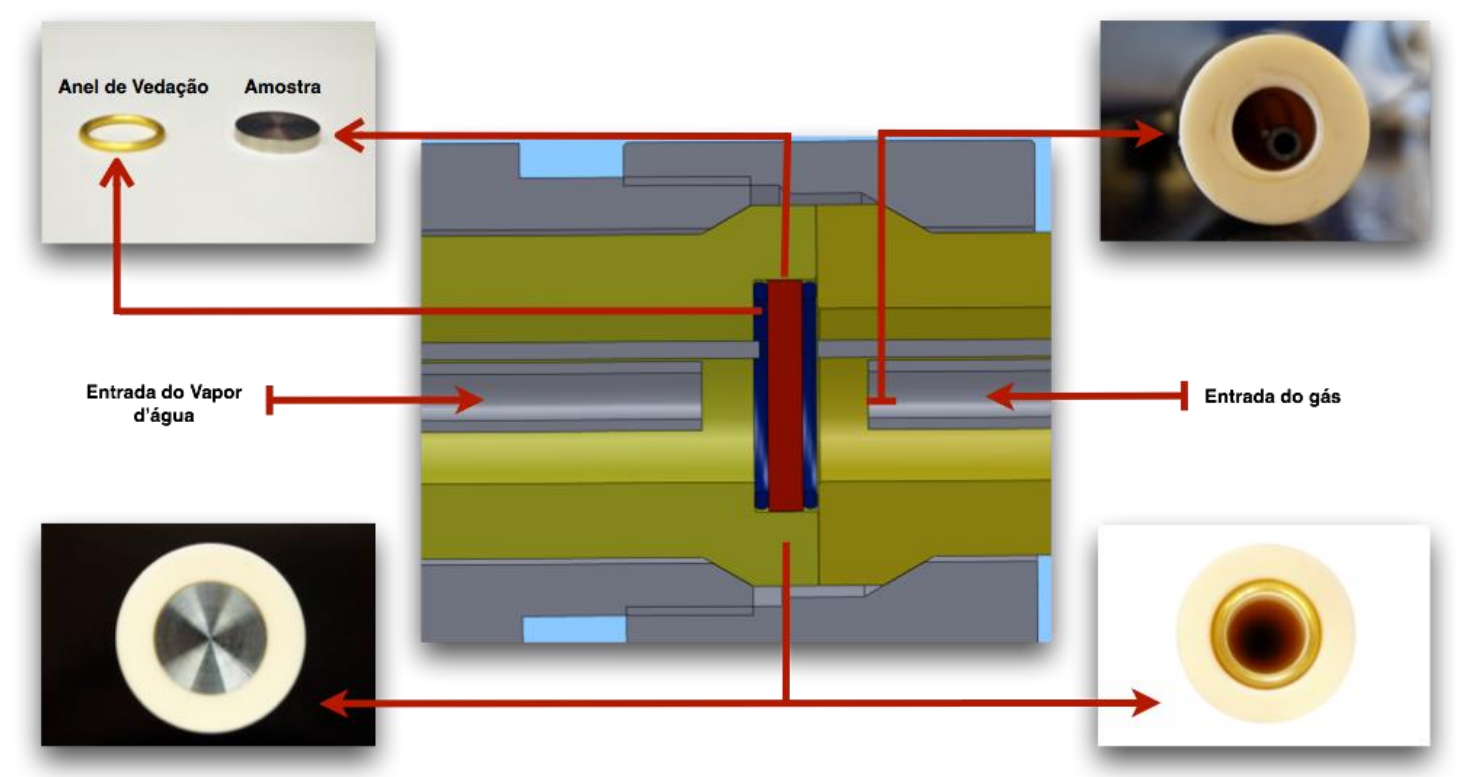

Figura 1: Esquema do forno de atmosfera dupla onde a amostra é exposta a vapor d'água de um lado e contendo $70 \% \mathrm{CO}_{2}-1 \% \mathrm{SO}_{2}-29 \% \mathrm{H}_{2} \mathrm{O}$ do outro.

Após os ensaios as amostras foram analisadas em microscópios ótico, eletrônico de varredura (MEV), microsonda e focous ion bean (FIB). Também foi utilizado EDS para caracterizar as camadas de óxidos formadas.

\section{RESULTADOS E DISCUSSÃO}

\subsection{Atmosfera Simples}

Os aços P3, P4 e P5 foram expostas aos gases 1 e 3 em atmosfera simples durante $1000 \mathrm{~h}$ a $600^{\circ} \mathrm{C}$. Todos os aços tiveram uma corrosão mais severa no Gás 3 , que contém $\mathrm{H}_{2} \mathrm{O}$. No Gás 1 , uma camada de óxido protetora rica em $\mathrm{Cr}$ se formou em todos os aços e a análise da superfície indica a formação de poucos nódulos ricos em Fe (Figura 2).

\footnotetext{
* Contribuição técnica ao $69^{\circ}$ Congresso Anual da ABM - Internacional e ao 14ํㅡㄹ ENEMET - Encontro Nacional de Estudantes de Engenharia Metalúrgica, de Materiais e de Minas, 21 a 25 de julho de 2014, São Paulo, SP, Brasil.
} 

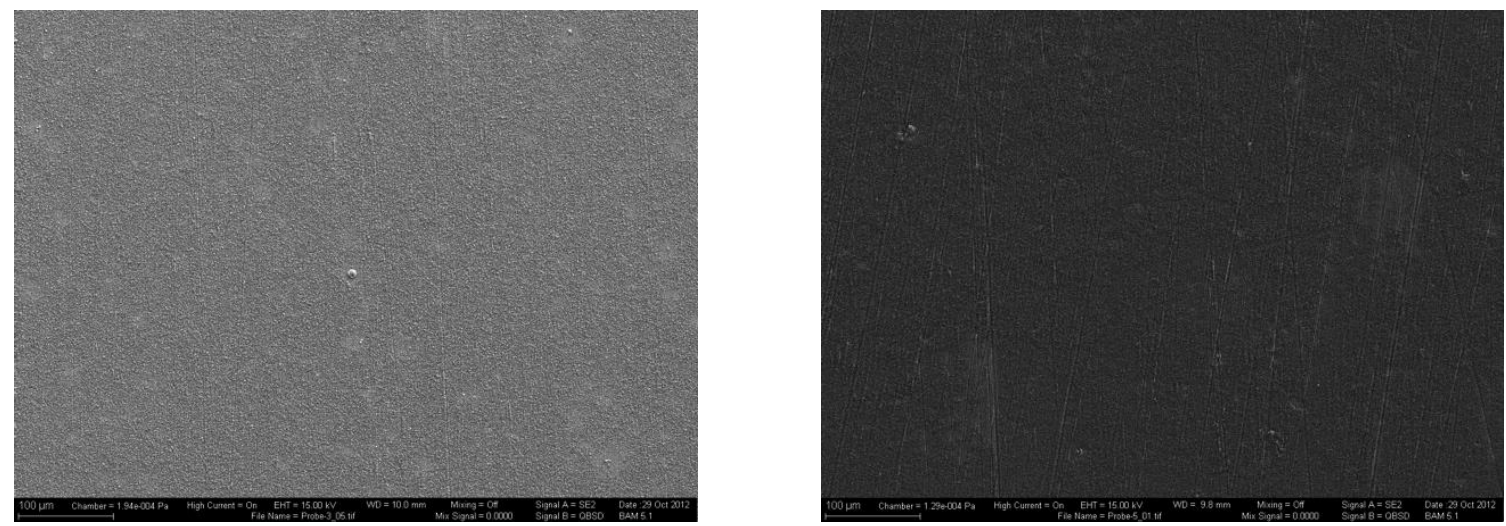

Figura 2: Aços P3 (esquerda) e P5 (direita) expostos ao Gás 1 em uma atmosfera simples à $600^{\circ} \mathrm{C}$ durante $1000 \mathrm{~h}$.

Quando expostos ao Gás 3 houve um aumento na quantidade de nódulos ricos em Fe formados (Figura 3). A composição química dos nódulos é semelhante em todas as três ligas e eles são compostos por uma camada externa rica em Fe como caracterizado no EDS de um nódulo da liga P4 (Figura 4).
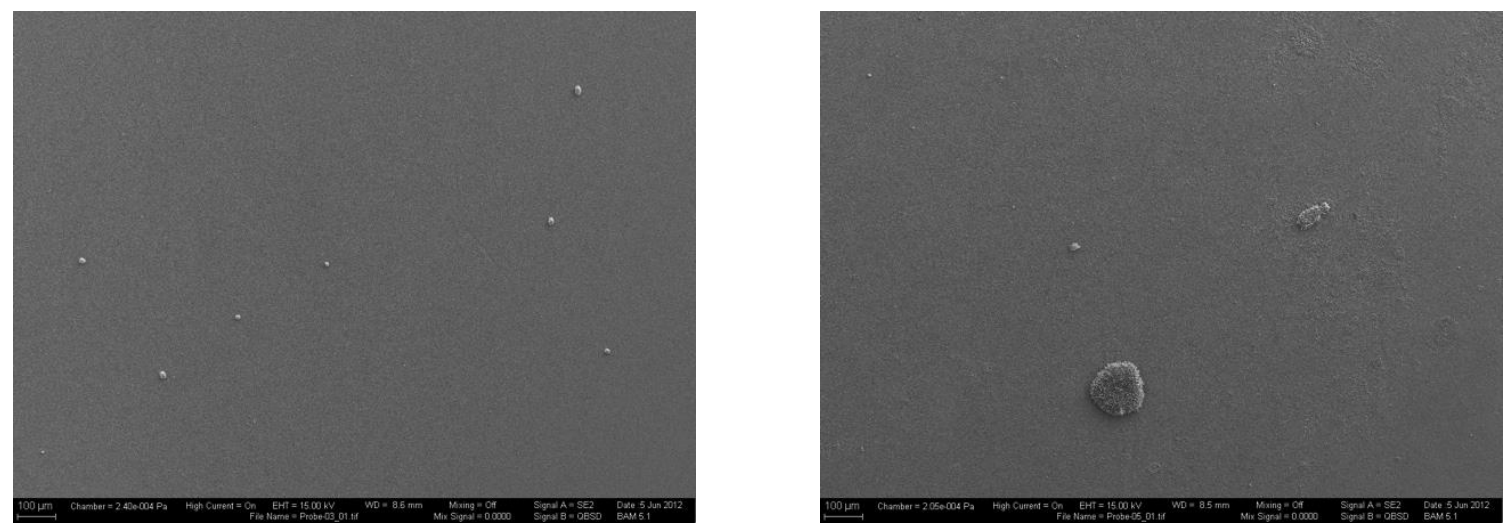

Figura 3: Aços P3 (esquerda) e P5 (direita) expostos ao Gás 3 em uma atmosfera simples à $600^{\circ} \mathrm{C}$ durante $1000 \mathrm{~h}$.

\footnotetext{
* Contribuição técnica ao 69 Congresso Anual da ABM - Internacional e ao 14ํㅡㄹ ENEMET - Encontro Nacional de Estudantes de Engenharia Metalúrgica, de Materiais e de Minas, 21 a 25 de julho de 2014, São Paulo, SP, Brasil.
} 


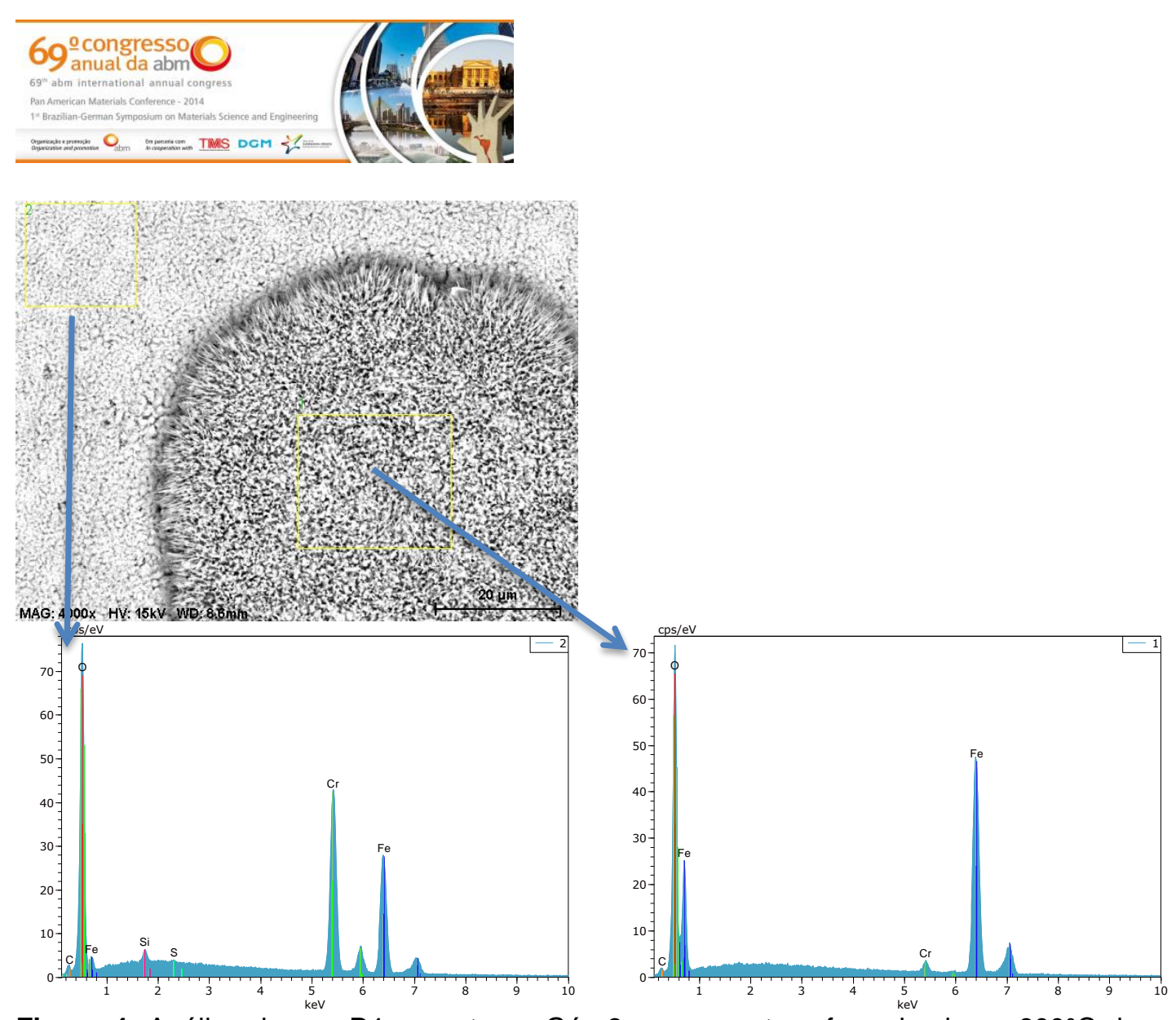

Figura 4: Análise do aço P4 exposto ao Gás 3 em uma atmosfera simples a $600^{\circ} \mathrm{C}$ durante $1000 \mathrm{~h}$. EDS mostrando um nódulo rico em Fe em uma matriz formada por óxidos de Cr.

No Aço P4 a formação de ferrita pode ser observada em microscópio ótico e em MEV na Figura 5. Os carbonetos $\left(\mathrm{M}_{23} \mathrm{C}_{6}\right)$ foram consumidos na formação da camada de óxido rica em $\mathrm{Cr}$, o que aumentou a mobilidade das interfaces do grão de ferrita.
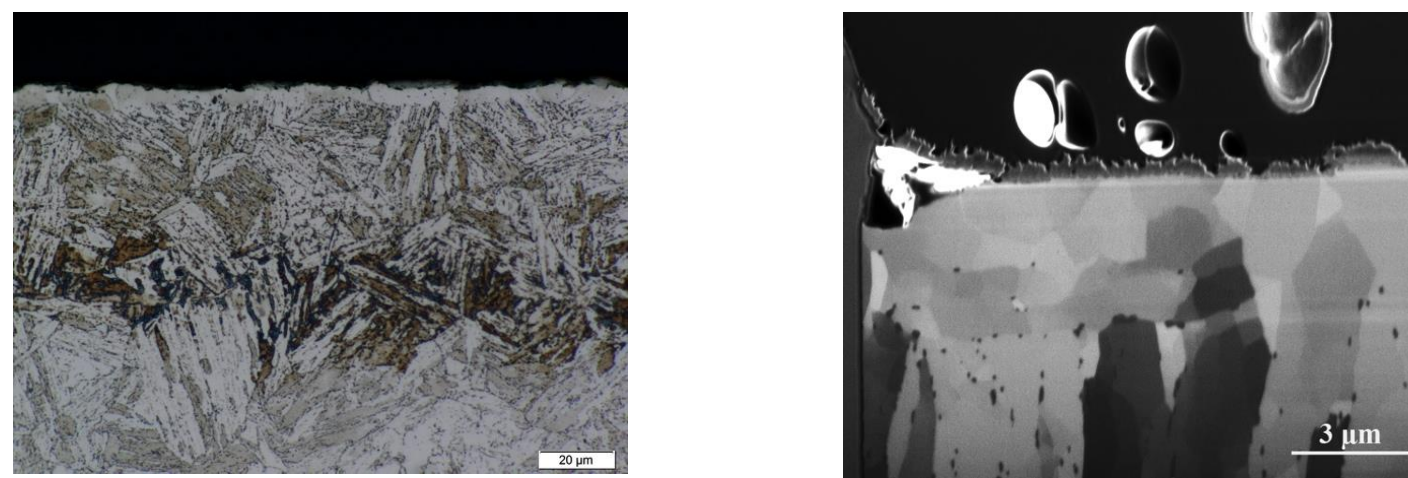

Figura 5: Micrografias do aço em microscópio ótico (esquerda) e FIB (direita) do aço P4 exposto ao Gás $3 \mathrm{em}$ uma atmosfera simples a $600^{\circ} \mathrm{C}$ durante $1000 \mathrm{~h}$. $\mathrm{O}$ aço apresenta uma camada de ferrita com poucos carbonetos perto da interface metal/óxido.

\subsection{Atmosfera Dupla}

Em condição de atmosfera dupla houve, na maioria das amostras, uma aceleração na oxidação dos aços tanto no Gás 1 quanto no Gás 3. Esta aceleração pode ser observada tanto pelo aumento do número e tamanho dos nódulos ricos em $\mathrm{Fe}$ formados quanto pela camada de ferrita mais espessa que em atmosfera simples formada na região sob a interface metal/óxido.

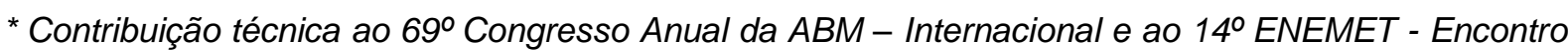
Nacional de Estudantes de Engenharia Metalúrgica, de Materiais e de Minas, 21 a 25 de julho de 2014, São Paulo, SP, Brasil.
} 
A maior formação de nódulos pode ser melhor observada na amostra P5 exposta ao Gás 1 (Figura 6). Neste aço houve uma grande formação de nódulos que coalesceram no centro da amostra formando uma camada contínua.
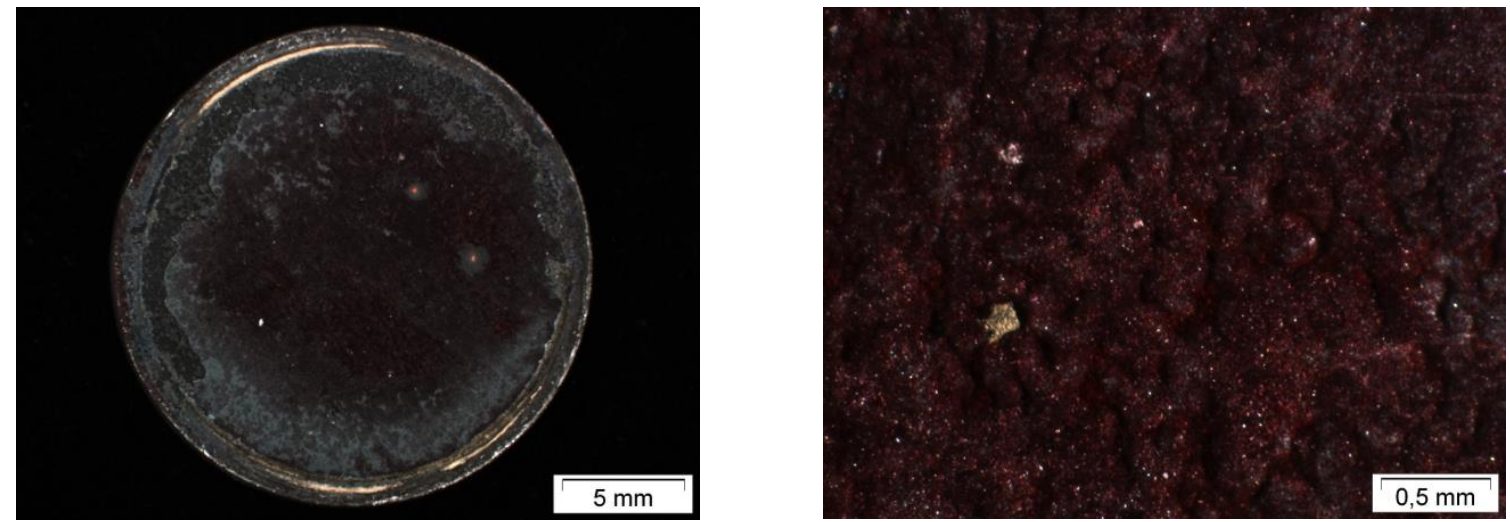

Figura 6: Micrografias do aço P5 exposto ao Gás 1 em uma atmosfera dupla a $600^{\circ} \mathrm{C}$ durante $1000 \mathrm{~h}$. Em condição de atmosfera dupla houve maior formação de nódulos ricos em Fe neste aços que em atmosfera simples. No centro da amostra houve um coalescimento dos nódulos formando uma camada contínua de óxido rico em Fe.

Pela a imagem de MEV da Figura 7 é possível observar que a camada contínua é formada pelo coalescimento de nódulos de óxidos. A análise de EDS indica que esta camada de óxidos é composta por hematita (fase vermelha observada na Figura 6) e magnetita na parte externa e espinélio de ferro e cromo na camada interna. Enxofre também foi encontrado no espinélio, mas não nos óxidos de ferro.

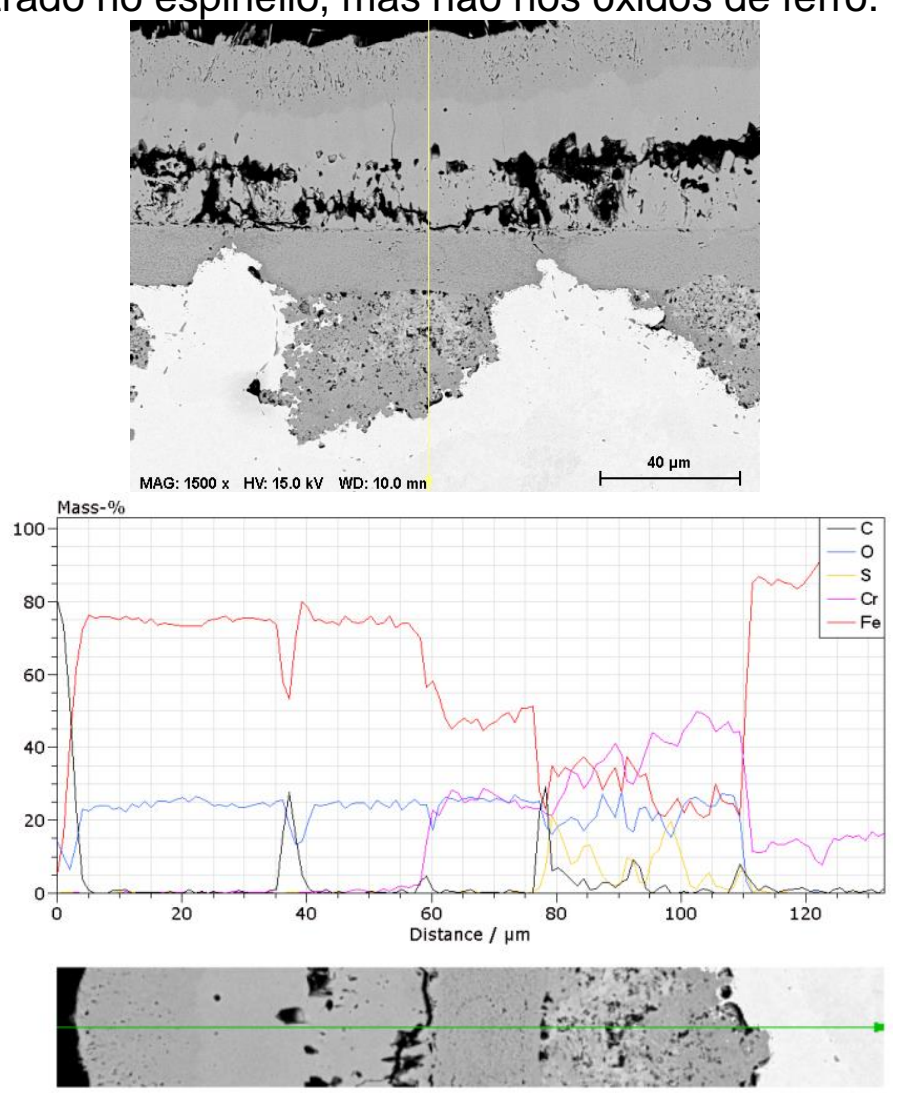

Figura 7: Análise de EDS do aço P5 exposto ao Gás 3 em uma atmosfera dupla a $600^{\circ} \mathrm{C}$ durante 1000h. A camada externa de óxido é formada for hematita $\left(\mathrm{Fe}_{2} \mathrm{O}_{3}\right)$ e magnetita $\left(\mathrm{Fe}_{3} \mathrm{O}_{4}\right)$ enquanto que a camada interna é formada por espinélio de ferro e cromo $\left(\mathrm{Fe}, \mathrm{Cr}_{2} \mathrm{O}_{4}\right)$.

\footnotetext{
* Contribuição técnica ao 69ํ Congresso Anual da ABM - Internacional e ao 14ํㅡㄹ ENEMET - Encontro Nacional de Estudantes de Engenharia Metalúrgica, de Materiais e de Minas, 21 a 25 de julho de 2014, São Paulo, SP, Brasil.
} 


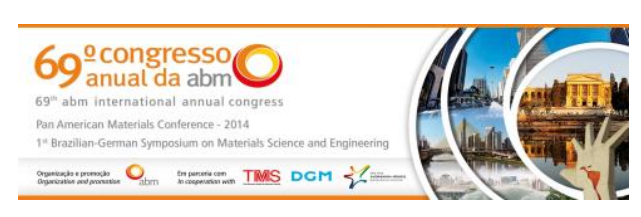

Os aços P3 e P4 não formaram uma camada contínua como o aço P5, mas formaram mais nódulos em atmosfera dupla que em atmosfera simples. Nos dois aços, houve a formação de uma camada de ferrita sob a interface metal/óxido (Figura 1). Comparando as imagens das Figuras 5 e 6, pode-se observar que no aços P4 a espessura da camada de ferrita é maior na condição de atmosfera dupla que na condição de atmosfera simples. Isto indica que houve um maior consumo de carbonetos para formar a camada de óxido em atmosfera dupla que em atmosfera simples.
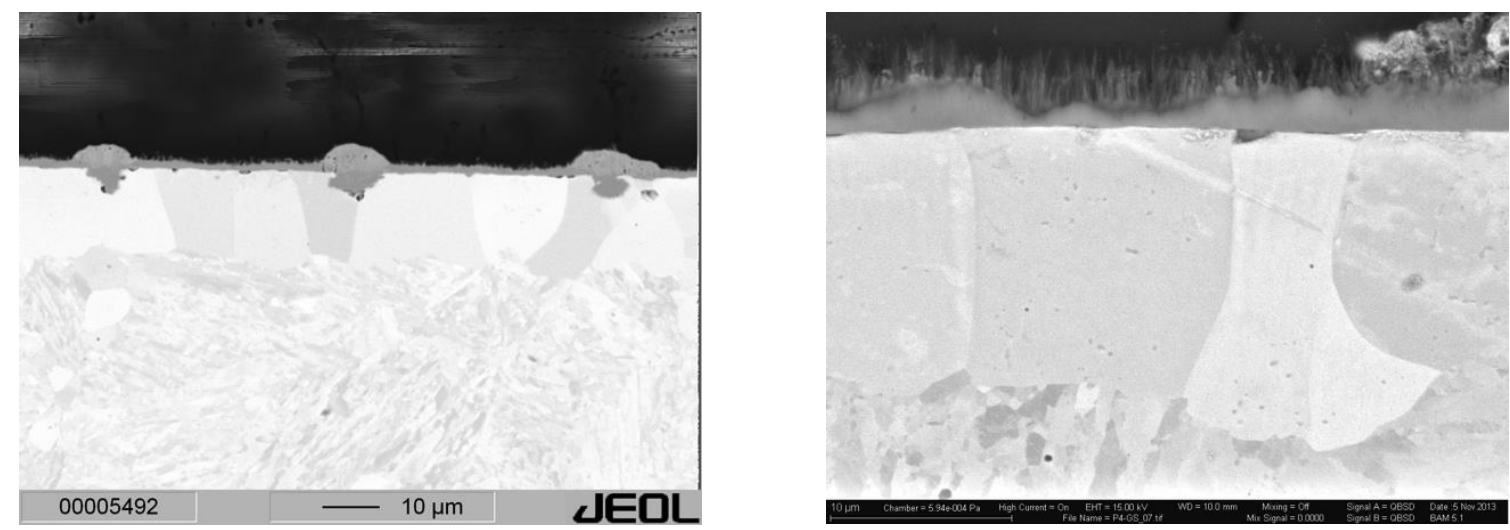

Figura 1: Micrografias dos aços P3 (esquerda) e P4 (direita) expostos ao Gás 3 em uma atmosfera dupla a $600^{\circ} \mathrm{C}$ durante $1000 \mathrm{~h}$. Em ambos os aços, uma camada de ferrita se formou sob a interface metal/óxido e os dois materiais apresentaram maior formação de nódulos que em atmosfera simples.

Os resultados apresentados neste trabalho corroboram os diversos estudos [10-15] que apresentaram uma maior corrosão em atmosfera dupla que em atmosfera simples em aços. Os resultados indicam que apesar de a microestrutura e a composição química (variação de cobalto e carbono) ter tido pouca influência na oxidação em atmosfera simples, estes fatores influenciaram a oxidação em atmosfera dupla. A camada de óxido nos aços martensíticos é formada e mantida pelo consumo de carbonetos ricos em $\mathrm{Cr}$ na região sob a interface metal/óxido. No aço ferrítico, que não apresentou carbonetos, a formação de nódulos ricos em óxidos de Fe foi mais severa devido a menor disponibilidade de Cr para a formação da camada de óxido protetora. A camada protetora, principalmente a crômia $\left(\mathrm{Cr}_{2} \mathrm{O}_{3}\right)$, também diminui o efeito da atmosfera dupla como demonstrado por Tanaka et al. [17].

Os resultados em atmosfera simples mostraram que a maior concentração de $\mathrm{H}_{2} \mathrm{O}$ em atmosferas ricas em $\mathrm{CO}_{2}$ aumenta a oxidação dos aços.

\section{CONCLUSÃO}

As três amostras de aços experimentais com $14 \% \mathrm{Cr}$ e com diferentes teores de cobalto e carbono apresentaram resultados similares em atmosferas simples e tiveram um aumento na corrosão quando expostos ao gás com maior teor de $\mathrm{H}_{2} \mathrm{O}$. Quando os mesmos aços foram expostos à atmosfera dupla, houve uma corrosão mais severa que em atmosfera simples. Nos aços martensíticos, o consumo de carbonetos na região sob a interface metal/óxido favoreceu a formação de uma camada de óxido rica em $\mathrm{Cr}$ e ao crescimento de ferrita. A influência da atmosfera dupla na corrosão foi maior no aço ferrítico devido à menor disponibilidade de $\mathrm{Cr}$ para a formação da camada protetora.

\footnotetext{
* Contribuição técnica ao $69^{\circ}$ Congresso Anual da ABM - Internacional e ao 14ํㅡㄹ ENEMET - Encontro Nacional de Estudantes de Engenharia Metalúrgica, de Materiais e de Minas, 21 a 25 de julho de 2014, São Paulo, SP, Brasil.
} 


\section{Agradecimentos}

Os autores agradecem ao CNPq, CAPES, DAAD e ao Bundesanstalt für Materialforschung und -prüfung (BAM) pelo apoio financeiro ao projeto.

\section{REFERÊNCIAS}

1 IEA. Clean Energy: Progress Report. IEA. Paris. 2011.

2 IEA. Tracking Clean Energy Progress 2013. IEA. [S.I.]. 2013.

3 IEA. World Energy Outlook 2013 Factsheet. IEA. [S.I.]. 2013.

4 Foy K. History and State-of-the-Art of Fuel Fired Zero Emission Power Cycles.International Journal of Thermodynamics, 2006; 9(2): 37-63. ISSN 1301-9724.

5 Huenert D, Schultz W, Kranzmann A. Corrosion of steels in $\mathrm{H} 2 \mathrm{O}-\mathrm{CO} 2$ atmospheres at temperatures between $500^{\circ} \mathrm{C}$ and $700^{\circ} \mathrm{C}$. 15th nternational Conference on the Properties of Water and Steam. Berlin: [s.n.]. 2008.

6 Hünert D. Korrosionsprozesse und Aufkohlung von ferritisch-martensitischen Stählen in H2O-CO2 Atmosphären. BAM. Berlin. 2010.

7 Abellán, PJ, et al. Scale formation mechanisms of martensitic steels in high $\mathrm{CO} 2 / \mathrm{H} 2 \mathrm{O}-$ containing gases simulating oxyfuel environments. Materials at High Temperaturs, 2009;26(1):63-72.

$8 \mathrm{Mu} \mathrm{N}$, et al. Water Vapor Effects on the Oxidation Behavior of $\mathrm{Fe}-\mathrm{Cr}$ and $\mathrm{Ni}-\mathrm{Cr}$ Alloys in Atmospheres Relevant to Oxy-fuel Combustion. Oxidation of Metals, Maio 2012.

9 Meier GH, et Al. Effect of Alloy Composition and Exposure Conditions on the Selective Oxidation Behavior of Ferritic $\mathrm{Fe}-\mathrm{Cr}$ and $\mathrm{Fe}-\mathrm{Cr}-\mathrm{X}$ Alloys. Oxidation of Metals, 2010;74:319-340.

10 Nakagawa K, Matsunaga Y, Yanagisawa T. Corrosion behavior of steels on the air side of boiler tubes in steam/air dual environment. Materials at High Temperature, 2003;20(1):67-73.

11 Yang Z, et al. Anomalous corrosion behavior of stainless steels under SOFC interconnect exposure conditions. Electrochemical and SolidState Letters, 2003;6(10):B35-B37.

12 Yang Z, et al. Oxidation behavior of ferritic stainless steels under SOFC exposure conditions. Jornal of the Electrochemical Society, 2004; 151(12):B669-B678.

13 Yang Z, et al. High temperature oxidation/corrosion behavior of metals and alloys under a hydrogen gradient. International Journal of Hydrogen Energy, 2007;32:3770-77.

14 Yang Z, et al. Effects of water vapor on oxidation behavior of ferritic stainless steels under solid oxide fuel cell interconnect exposure conditions. Solid State lonics, 2005;176:1495-1503.

15 Holcomb GR, et al. Dual-environment effects on the oxidation of metallic interconnects. Journal of Materials Engineering and Performance, 2006; 15: 404-409.

16 Kurokawa $\mathrm{H}$, et Al. Hydrogen Permeation Through Fe-16Cr Alloy Interconnect in Atmosphere Simulating SOFC at $1073 \mathrm{~K}$. Journal of The Electrochemical Society, 2004;151(8):A1264-A1268.

17 Tanaka M. et al. Hydrogen Permeability through n-type Cr2O3 Scale at $1273 \mathrm{~K}$ under the Oxygen Activities of $1.610-18$ - 1.0 10-16. ISIJ International, 2011;51:638-644.

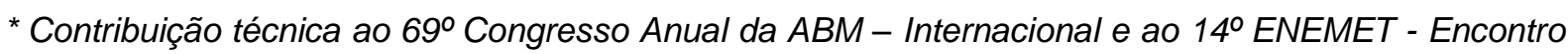
Nacional de Estudantes de Engenharia Metalúrgica, de Materiais e de Minas, 21 a 25 de julho de 2014, São Paulo, SP, Brasil.
} 